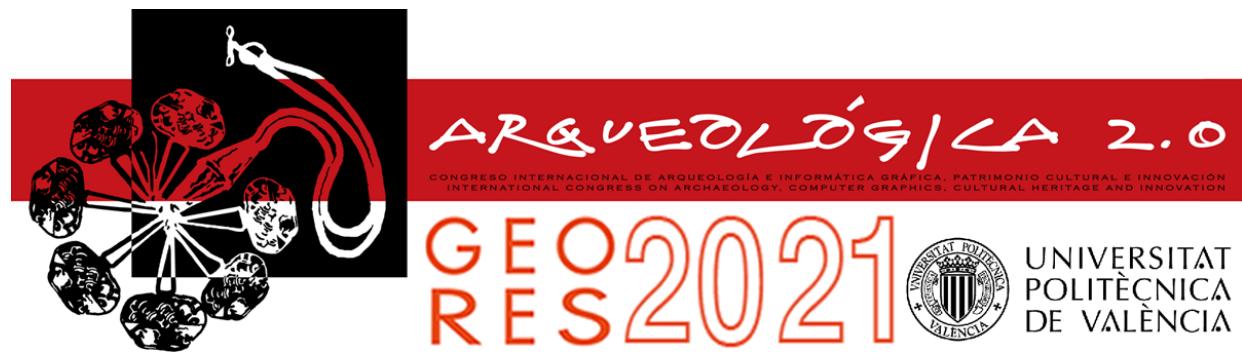

Proceedings of the joint international event $9^{\text {th }}$ ARQUEOLÓGICA

$2.0 \& 3^{\text {rd }}$ GEORES

Valencia (Spain).

26-28 April 2021

\title{
CONSIDERATIONS AND QUESTIONS DERIVED FROM THE APPLICATION OF A SCAN-TO-BIM MODELING PROCESS OF A HISTORICAL PUBLIC BUILDING
}

\author{
Franco Guzzetti", Karen L. N. Anyabolu, Francesca Biolo, Lara D’Ambrosio
}

Department of Architecture, Built Environment and Construction Engineering, Politecnico di Milano, Via Ponzio 31, 20133 Milan, Italy. franco.guzzetti@polimi.it; karenlara.anyabolu@polimi.it; francesca.biolo@polimi.it; lara.dambrosio@polimi.it

\begin{abstract}
:
According to the new Italian regulation (DM 560-17), every building project has to present a BIM model. The purpose of this new attitude is to better manage every single part of the building process, until the maintenance in the years. With these terms, public administrations should have guidelines to collect different data projects in a standard way for an optimal organization. The importance of standards is even more felt with HBIM, so when the subjects are historical buildings and Architectural Heritage. Analysis of the case study and its digitization process has brought to light many problems, some of them directly regarding the software, others are critical issues discussed in the following paper. The teamwork highlights the modelling phase's criticalities for irregular and complex elements, a central feature for historical buildings but also an important limit for today's BIM software. Secondly, this work regards essential data integrated to complete historical BIM. Lastly, the theme of the digital-twin, that is meant as a complete, and as-is model. The main issue is to understand if this unique detailed model - with the same BIM's LOD of new buildings - is enough to aggregate all the information or is it better to create multiple 3D models based on different aims: structure, history, maintenance, and so on. Some examples of critical points are exposed and discussed, referring to a hypothetic conservation project.
\end{abstract}

Keywords: scan-to-BIM, HBIM, historical building, public administration, BIM modelling

\section{Introduction}

\subsection{Legislative framework and public administration}

In the last years, the regulation of public tender has changed following the development of new technology. One of the main aims is to use the BIM methodology in the design and construction phases. The introduction of this tool represents an international reform, which has led to various results in different countries in term of standardization. The BIM presence is already deeply rooted in the same states like Germany, the United Kingdom and other countries of Northern Europe. Instead, the deadline for Italy is in 2025 . For that period, every project (new, restoration, enlargement, infrastructures) should be presented in BIM (Ministry of Infrastructure and Transport, Ministerial Decree, 1-122017, n. 560).

Furthermore, respecting the no soil consumption's purpose, many regional and municipal funding is arisen to restore buildings in the old town and abandoned constructions, especially for public schools.
In this period, projects on existing constructions have augmented rapidly, and most of the time, buildings are historically significant and they show the result of years of changing. To create BIM, it is necessary to start with an adequate survey phase (Osello, Lucibello, \& Morgagni, 2018; Tommasi, Fiorillo, Jiménez Fernàndez-Palacios, \& Achille, 2019) that allows us to obtain all the information to model the building; then, it is possible to proceed with the project, construction, and maintenance. Considering the entire life cycle of a structure, from public tender to facility management in the years, is one of the principal innovations with a BIM, Building Information Model.

This kind of process has a higher level of complexity in an existing building than in a new one due to irregularity of geometries, particular elements, difficulties obtaining information, and lack of software commands (Guzzetti, Anyabolu, D'Ambrosio, Marchetti, \& Sarrecchia, 2018).

The experience of teamwork aims to explain different issues individuated. The interaction between laser scanner survey, historical investigations, and BIM standards allow creating of a model suitable for a hypothetic conservation and renovation project. The potentiality of digitization in every sector is crucial, especially for Smart Cities and all the loT applications for the built (Angelidou, Angelidou, Karachaliou, \&

“Corresponding Author: Franco Guzzetti, franco.guzzetti@polimi.it 
Stylianidis, 2017; Bie et al., 2018; Atta \& Talamo, 2019; Lerario \& Varesano, 2020).

In this case, the Scan-to-BIM method is focused on framing a historical BIM into guidelines that are necessary for the municipal technical office to manage its immovable properties. The challenge is to keep together an official regulation for Facility Management and generic quantification of spaces in the municipality and maintain features, details, and structural and historical information fundamental in an ancient building.

\subsection{Condition for exploiting the potential of BIM}

Creating a BIM has an extreme value in the management view; it permits working with a long-term vision on a building. It is possible to compute construction costs and defining strategy for the next years, calculating the price of a restructuring or maintenance, quantifying changes in the energetic building class considering the substitution of several elements. For instance, the shell with fine quality materials allowed to save a considerable amount of money in the years, and with a BIM, a direct and fast comparison is feasible.

Furthermore, this kind of analysis is suited to choose adequate materials considering CAM (Criteri Ambientali Minimi - Minimum Environmental Criteria): the Italian regulation for better building recycling management.

All things considered, the model should follow official rules to be aligned to municipal documentation and respect criteria of calls for public funding, usually concerning structural analysis, landscape, and contest evaluation, historical information and consideration, maintenance of relevant historical-architectural elements. Another important theme is the valorization of the building that is difficult to show and explain through BIM if the model tends to become too simplified according to the guidelines. How can BIM maintain together all the requirements? Is it possible to have an actual digital twin referring to a historical building?

Nowadays, many different H-BIM approaches are analyzed (Lopez, Lerones, Llamas, Gomez-GarciaBermejo, \& Zalama, 2018): creating mesh and using NURBS are appropriate solutions to follow the realistic shape of the irregular and complex building (Barazzetti, Banfi, Brumana, \& Previtali, 2015) visible in a point cloud. Still, models do not have standard elements, of course. Different LOD can be defined in modelling (BIMForum, 2018), or GoG referring to NURBS (Banfi, 2017), but it is necessary to consider a high level of detail to obtain correct BIM, both from a geometrical and informative point of view. It is interesting comparing a new building model and an existing building model. For the first one, it is usually feasible to reach LOD 500 (LOD F for Italian scales) the same LOD of the as-built (Mirarchi, Lupica Spagnolo, Daniotti, \& Pavan, 2020) owing to all the data present in the design phase (until technology node and detailed stratigraphy). It is more difficult for the second one to obtain this high LOD level due to the lack of information on the construction phase (materials, facilities, dimensions); the available documentation is not often enough. To gain the correct information and create detailed BIM is necessary to consider teamwork to integrate different knowledge and investigations
(Tommasi, Fiorillo, Jiménez Fernàndez-Palacios, \& Achille, 2019).

\section{Case study: Palazzo Trivulzio's model}

\subsection{Historical building and survey phase}

The building analyzed for this research is Palazzo Trivulzio, situated in the old town of Melzo, $20 \mathrm{~km}$ east of Milan. The construction has great importance in the history of the entire city; it results from numerous overlays, enlargement, and changes of use destinations over eight centuries that lead to today's complex building.

In the first place, there was the castle of which today is possible to recognize the XIII century tower and the internal facade of the west wing facing the courtyard, with pointed arches. Between 400 and 500, the building consisted of three courts, and now only one of them is visible. In 1600 it became a representative villa of the local landlord, and on this occasion, various chambers were enriched with frescoes, and different spaces were modified. Unfortunately, two centuries after this period, a change of ownership was made, which leads to a period of decline.

In the middle of 1800 , the municipality acquired the palace (precisely in 1866) to host a public school. In the last century, in the first decades, a movie theater was realized that is still in function (north part), while, since 1980, the south-west sector was restored to host public library and communal halls and spaces. With the inauguration of a new library in 2014, its communal part is currently little used.

Together with other 23 buildings, property of the Municipality of Melzo, Palazzo Trivulzio is considered inside a massive pluriannual project that aims to digitized public buildings creating BIM to improve facility management. For this reason, the modeling phase involves the use of specific guidelines (Di Giuda et al., 2020) defined by BIMGroup, a Politecnico di Milano's team in the Department of Architecture, Built Environment and Construction Engineering. The team work in the construction field, primarily to obtain informative models for building maintenance over time. Simultaneously, as said before, the BIM should contain the information for conservation and design phases.

The geometrical survey has been conducted by Digitarca s.r.l.s. using a static laser scanner; in three days on the field: it has been carried out 300 scans for both exterior path and interior rooms, and in total, $5.400 \mathrm{~m}^{2}$ of plot and $20.100 \mathrm{~m}^{3}$ of the building are investigated (Fig. 1).

The complete point cloud (after a cleaning step) has a size of 23,7 GB; the product is indispensable to modelling but not by itself: it is necessary an accurate and careful analyzing phase to generate a usable model or to extract the information needed.

\subsection{Modelling settings}

The geometrical modelling phase is conducted with Revit Autodesk software to follow inputs defined by the Municipality of Melzo in collaboration with BIMGroup. To work correctly is fundamental to choose in advance the level of detail and level of accuracy, in agreement with the ultimate goal of the model as happens for typical $2 \mathrm{D}$ 
drawings. Considering the graphics error at a medium scale of 1:50, the model permits a tolerance of $+/-2 \mathrm{~cm}$, except for particular elements with more close attention to details described in the official guidelines.

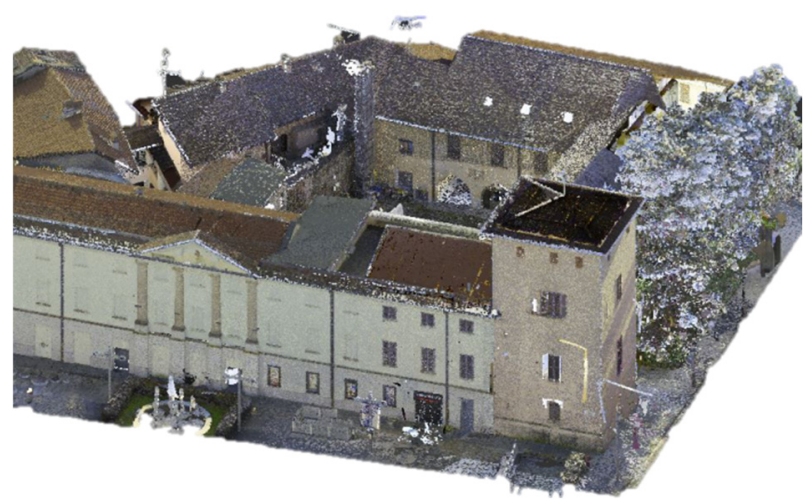

Figure 1: View of point cloud generated from the laser scanner survey

Despite this correct process to define tolerance, in the case study, the geometric irregularities generate considerable problems in the modelling phase (Osello, Lucibello, \& Morgagni, 2018; Stanga et al., 2017; Tommasi, Fiorillo, Jiménez Fernàndez-Palacios, \& Achille, 2019, Banfi, 2020): the aim of Facility Management, in some cases, leads to excessive simplification of geometries, and this out-of-tolerance may invalidate some metric calculations, for instance, the number of finishes. This topic will be discussed in the following chapters. Anyway, the shared rules are useful to determine standards and a methodology for the classification and creation of elements.

It is known that BIM software is thought and set for new constructions, and in the case of historical buildings, many obstacles are shown. Modelling is intricate and complex. It is necessary to create numerous specific families and elements different from the standards ones or particular shapes of walls and floors; consequently, even the name categorization is more arduous to define.

Among the various issues, in the following pages, problems concerning wall modelling and settings are analyzed; the experience also shows that the same issues could be found in other irregular existing buildings because of the lack of the starting information.

\subsection{Geometrical modelling criticality in irregular elements: the creation of a wall on Revit}

In order to follow the guidelines defined by the Municipality, Autodesk Revit has been the best tool to model the building due to the creation of families with specific attributes and parameters. The aim of the regulatory documents is to set an adequate protocol for every type of building. The project is incredibly challenging because the examined building shows numerous particularities that could be better modelled exploiting other smart solutions and the integration among different software, as the use of NURBS (Barazzetti, Banfi, Brumana, \& Previtali, 2015). An example is the creation of an irregular wall.
In a new building, modelling is facilitated thanks to the detailed information of stratigraphy, features, technical data are defined in project phases and they are reported in relevant parameters. In the case of existing constructions, many precise details are missing, and the geometry of elements are not standard. Historical buildings present irregularities due to physical deterioration, structural failures, substitutions, and replacements carried out over time (Osello, Lucibello, \& Morgagni, 2018); but also because, in the past, the constructions were built differently from the standard way of today. The global deviation between the modelled element on Revit and the point cloud profile is bigger than the initially imposed $2 \mathrm{~cm}$ tolerance. The simplification in this software is necessary to create a model following standard rules, useful to manage a typical system. Still, in some cases, this method cannot solve the problems presented.

1) Variable thickness. A first example is related to the walls with a variable thickness both in plan and in section, with a regular course. The simplest solution is to create a local component because it is easier to modify considering shape and dimensions, but the element is hard to categorize. For this reason, in the project, it has been decided to choose a standard type of wall and then cut it with void elements (Fig. 2 ). In this way, the wall features are considered, but other problems arise: voids deleted part of the wall material, so the cut eliminates the finish and eventually interior layers. It is necessary utilizing a command to paint the wall in cut parts (Fig. 3). Furthermore, thick wall classification is wrong because of the voids that modified the wall geometry.

2) Elements of the junction. Another problematic case is the junction between not orthogonal elements, significantly more than two walls. This problem is exclusively a software lack because the automated solutions lead to different junction node conformations but it is hard to intervene manually (Fig. 4).

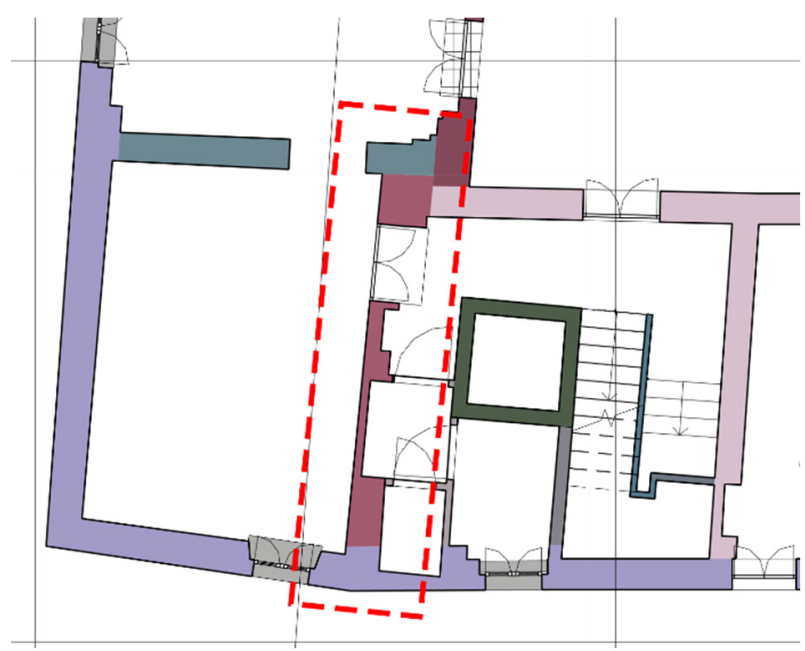

Figure 2: Masonry consisting of one type of wall with the application of voids. 


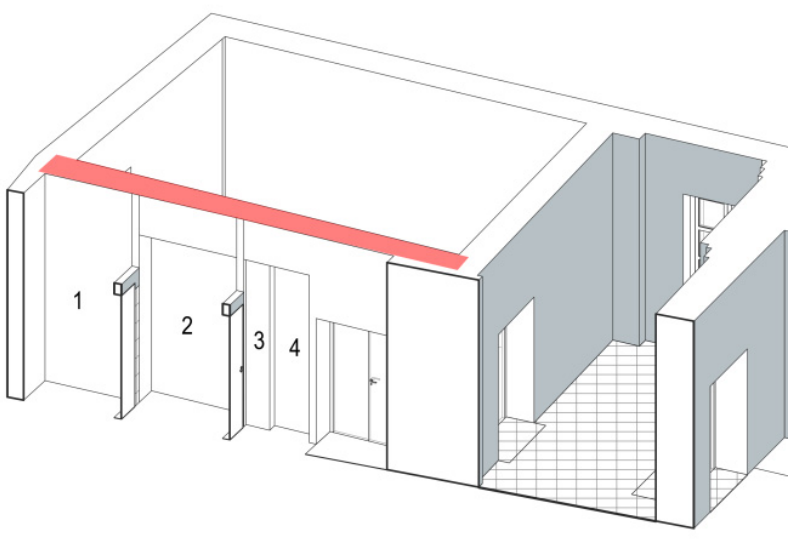

Figure 3: Numbers indicate different finish material in the same Revit type wall.

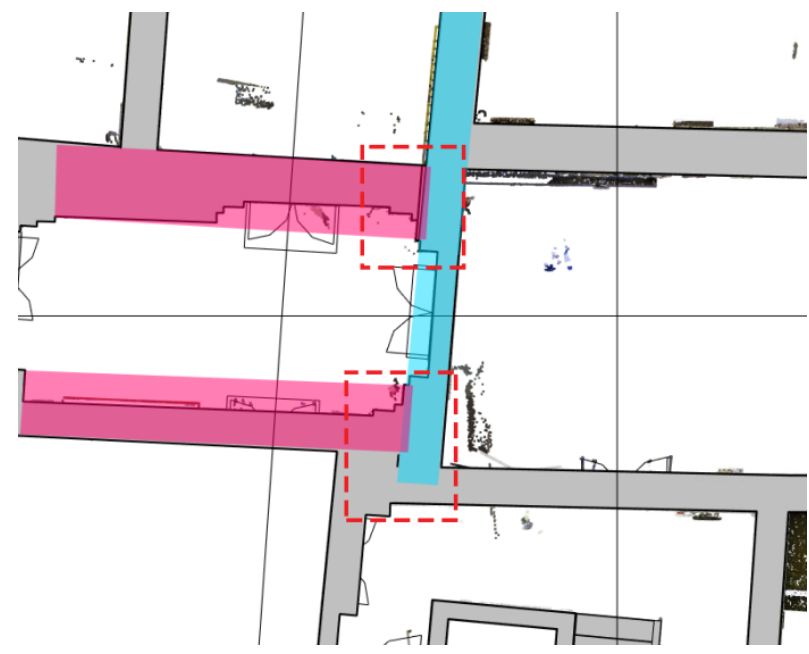

Figure 4: The overlay of not orthogonal walls may cause errors in the count of quantities.

In many cases, not orthogonal (and irregular) walls create critical points that remain unsolved. The element's position will be out of tolerance and may cause a problem in the next phases

3) Missing data. In Revit, to create a wall, it is necessary defining at least one material in the stratigraphy section. Considering that, in an existing building, the only way to precisely know the walls' characteristics is through coring or others not destructive investigations, walls are always described as "generic wall", a default element with unknown features. During point cloud analysis, it has been individuated different points where the material is undefined, but also geometry is unclear (Qiuchen \& Sanghoon, 2017). It might be interesting to distinguish between default material and non surveyed element.

As it happens in typical 2D drawings, in many cases is useful to individuate parts of building not known to understand which parts can be further investigated. Instead, in a BIM, every object is modeled with a determinate geometry. It is common to use the model as a complete and correct base for projects due to the higher technological level reached, and the model is derived from a high-precise laser scanner survey. It is crucial to annotate the lack of information and make them visible in the virtual model. The problem recurs in several constructive elements, i.e. vaults and slabs (Fig. 5) (Fig.6).

4) Partitions of a unique element. The next example analyzes an integral wall that, in the modeling phase, has to represent in different separated parts. The figure, constructively and visually, can be referred to as a unique wall with particular features. As mentioned, it is a single element; it was made simultaneously and with the same technology indeed. However, it presents narrowings because of the realization of some niches, and there is a change of parietal finish, for example, in sanitary facilities.

Ideally, in the 3D model, the wall should have a continuous development throughout its length with additional and editable elements, such as the change of finish or subtractions for the creation of voids (Fig. 7). Instead, working with Autodesk Revit, the wall results from the juxtaposition of as many walls as there are sections with different characteristics. The wall with the smaller thick will be a separate element from the bigger ones. The change of finish defines the creation of another type of masonry with slightly different characteristics. The software settings bring the user to this approach, according to the features of the wall family. However, considering, for example, this wall as a bearing one, such modelling would not be correct. Indeed, it would include attributes that are not relevant for constructing the building (such as finishes), and it invalidates the main characteristic of the element (the structural one).

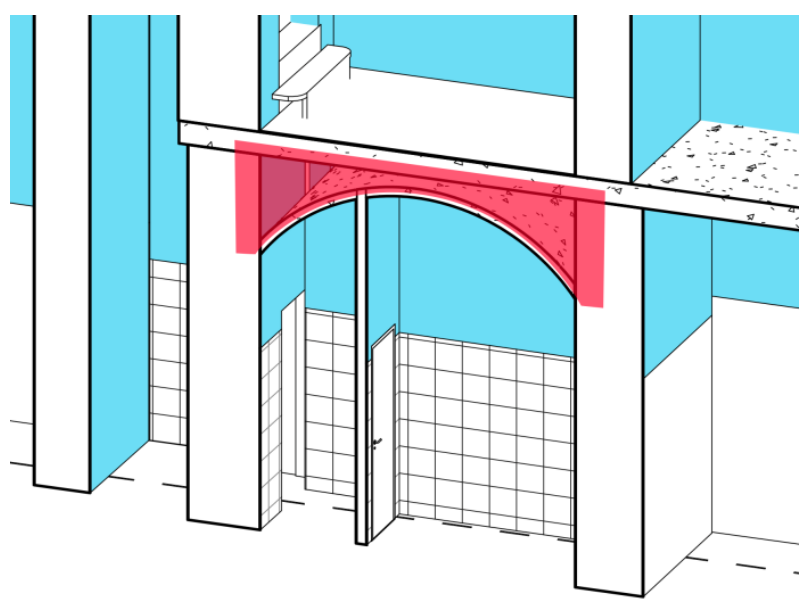

Figure 5: The not surveyed part between floor and intrados is highlighted. In this case, it was not possible to define correct thicknesses and stratifications.

The stratification of several historical phases and corresponding architectural elements is another aspect of masonry (extendable to other parts) (Stanga et al., 2017; Banfi, Stanga, \& Brumana, 2018). In historical buildings, the articulation of some objects and the processes that generated them are not often known. They are unique and not standard elements, and they are often unsolved points of the cognitive phase. In these situations, what is the more correct line to follow? Consider a junction point of two parts of the same building, built at different times. Observing the abnormal thickness and the various surface trends could be viewed as consisting of two juxtaposed structures. All this could result from the combination of two elements with a cavity, or even of a single wall with two layers of external finish. The latter 
solution is less logical but possible, according to the BIM scheme. The modeling of these three options has different consequences during the design and material cubic meter estimation or structural analysis (Fig. 8).

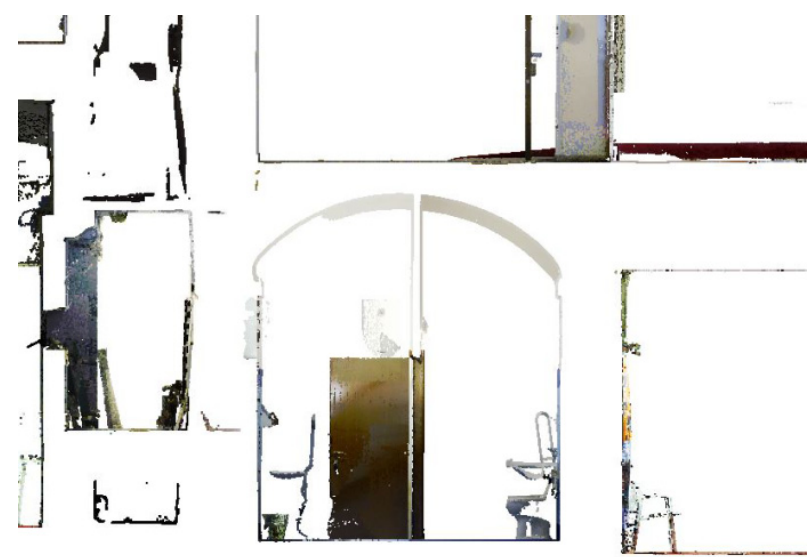

Figure 6: A point cloud section shows the thickness of the structures where is impossible to understand stratifications and nodes with certainty.

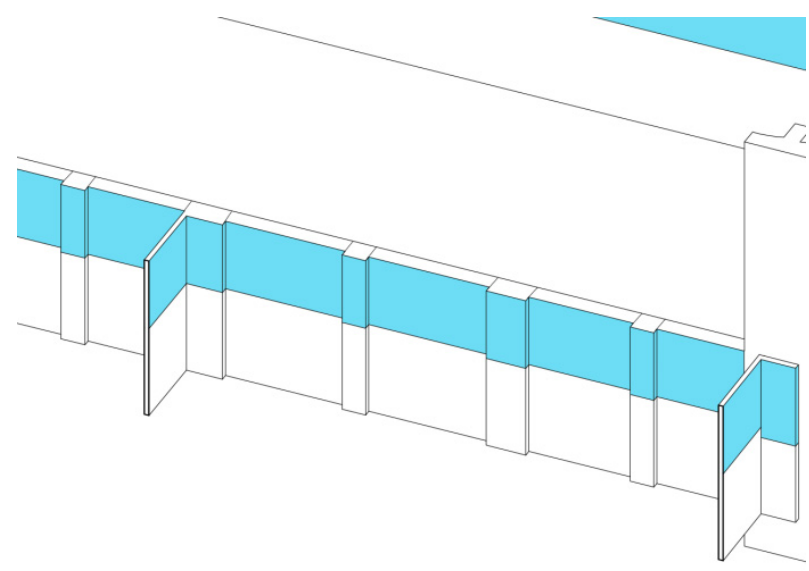

Figure 7: Partition of a wall owing to the difference in thickness of different parts.

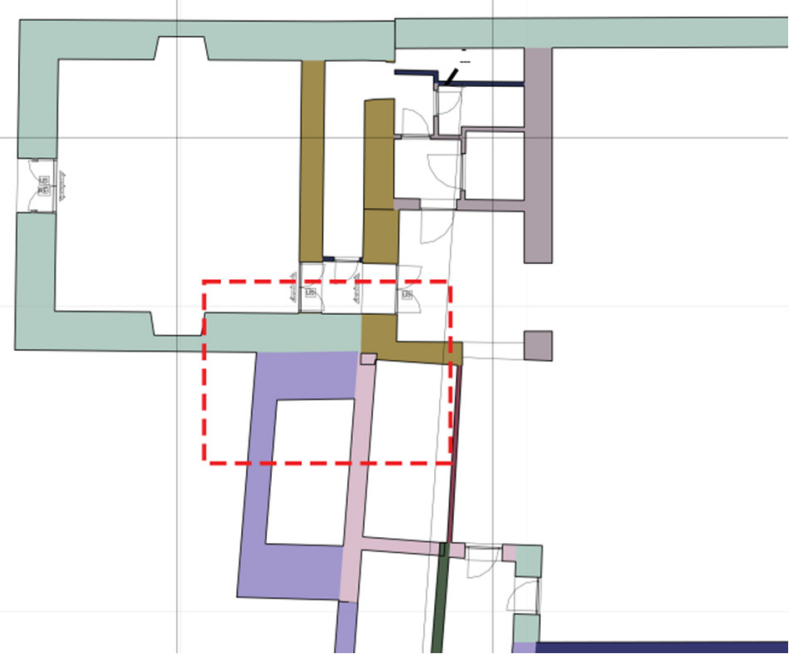

Figure 8: Junction of blocks built in different historical periods is created with different types of wall.

In the chance of a further development of the software, it would be helpful to add the feature of creating a new annotation for the element not surveyed, as explained in the following chapter.

\section{Considerations arising from the case study}

\subsection{Functionality of the BIM for historical buildings}

Setting up a BIM model of a preexistence requires a high level of knowledge of the structure itself, including as much information as possible. Historical buildings, therefore, imply a particular geometric and historical survey, typical of the conservation sector. A BIM system peculiarity is to reduce significantly, during the construction phase, the in-process variations. All this, thanks to its ability to manage information at every stage and part of the project. Precisely the in-process variations are one of the weaknesses in the construction sector, especially for public buildings due to the massive changes in the project costs, almost always adverse, and the difficulties in terms of consequences and operations managing. Designing, with this type of technology, to avoid variants as much as possible, is strategic. Therefore, this process has to be possible also for existing buildings that are often involved in complex redevelopment projects. But it will be possible only if the state of fact, with which the construction site then faces, is accurately detected (and modelled) and if software precisely responds to all the singularities found in an existing building. Otherwise, the BIM model needs to be reviewed during the work, with evidence manifestation. Standardizations in the modelling phase are understandable in new building construction, converting to an industrial approach (construction 4.0). However, they are not always acceptable in realizing a preexistence state of fact because they often involve massive adaptations of the project in modelling.

In many cases, BIM aims to be a digital twin of the built starts from the state of fact. If this could not be possible, it would be difficult to design and model MEP systems, structures, and other parts that need a precise model. The work of the various figures involved could not be organized, as indicated by the UNI 11337 legislation (Building and civil engineering works - Digital management of the informative processes, UNI11337:2017). The initial investment is necessary in order to model the different parts of the existing in an accurate way, and to collect data; this will allow the BIM to function properly in the long run. The problems above, are not affecting only the architectural model. BIM must be able to generate as directly as possible the structural resistance. Furthermore, BIM should support interaction with sub-services, urban areas development and related infrastructures and urban technological installations (Guzzetti, Anyabolu, D’Ambrosio, \& Marchetti, 2019).

Considering another point of view, it could be extremely interesting and useful a BIM for Facility Management (FM) as mentioned before (Di Giuda et al., 2020). But what are the problems, considering work in a BIM system aimed at Facility Management?

In order to obtain and visualize all the information needed for the management of a building, the idea of a precise and perfect digital twin could be really different. Despite creating a more schematic model, it is possible to relate 
all the information and parameters to a specific Autodesk Revit family. The element contains the correct data, it is computable, it has a particular positioning inside the model, therefore in an FM concept the precision of geometry is not essential. It is certain that some problem arises anyway, due to the software settings, but the scope of the model is reached. Following the guidelines, one of the most evident problem is the correct counting of the surfaces.

Considering a room, there is the necessity to count square meters of a specific type of finish, for instance, plaster. The irregular geometry of masonry it is defined using a void: in this way the finish of the wall is cutted out and the quantity of finishing change. In this case study, in order to follow as much as possible the point cloud, it is necessary to modify and trim numerous walls and this method invalidates the actual count. The solution described before is a procedure for in-place modelling. Therefore, the final result is correct but it is not among the standard attributes of the element.

\subsection{Possible parameters integration for a historical building}

Autodesk Revit defines the wall typologies organization. This software does not create a generic wall element to assign parameters that describe and complete it. In contrast, for each feature change, Autodesk Revit creates a new element in the library. In this way, the result is an endless list of walls with different and combined characteristics. This problem occurs not only with masonries but also with other building components, e.g., windows. All this, rapidly becomes challenging and limiting, working on a historical building.

Other parameters to explore:

- Element dating. Knowing the building's age leads to greater awareness in the design and maintenance phases. It can be better understood the needs of the building.

- Deterioration phenomena and information transmission. Always referring to the building, primarily to manage the design phase in a BIM environment, it is increasingly important to model this sort of data. But how can this information be inserted into a model? How can we make them easily readable and immediately noticeable? In Palazzo Trivulzio model, it has been created notes connected to the elements. This methodology is proving uncomfortable because it is not possible to query and to visualize these annotations automatically. Knowledge of the elements on this particular topic is a laborious and not immediate process. Revit should be able to manage new objects tool related to pathology and deterioration analyses and representation. The purpose is to obtain a BIM model aimed to facility management. In this context, it would be more useful to interact with this information and make them an integral part of the modeled objects. It is essential for promoting more performing interventions and actions closer to structure needs. For this reason, it is necessary to know these phenomena and their effects on the building system.

- Points of attention. As already mentioned before, it is not always possible to obtain all the necessary information relating to every element of a pre-existence and even more of a historical building. Questions are as many as the wall compositions, not visible structures or particular surveyed geometries hypothesis. It might be useful to add an extra phase dedicated to these uncertainties to highlight them and clarify the further possible interventions for cognitive purposes. It could be a layer where to insert all those elements on which there is not full knowledge. Therefore, they are points of attention in the intervention phase. This solution could be useful during the design phase as a knowledge indicator of building and starting point for further investigation activities.

During the work, it is resulted that is extremely difficult to create a definitive library in Autdodesk Revit, especially working with existing buildings because of their unique and non-standard elements. The list rapidly increases every time a new building is added. These derive not only from irregularities and object peculiarities but also from the settings of the software used. Therefore, is it conceivable imaging changes to software and operating standards to obtain a more organized and flexible system?

It has been analyzed a comparison with the GIS environment. As an example, in the DBT documentation (the CISIS Topography DataBase for Regione Lombardia), the classification "layer, theme, class" never cites geometric characteristics because the geometries are modelled or defined in the drawing. The geometric information is not explicit in the name of the element and it is not a distinctive attribute in the model: this allows the creation of a more orderly classification system. The experience with this different logical scheme leads to classifying elements in a more flexible way. The structure would be easily implementable with the use of codes. Moreover, the shapefiles can be punctual, linear or areal and the same organization could be used for deterioration mapping mentioned before.

\section{Conclusions}

Several critical issues have been highlighted during the modelling of Palazzo Trivulzio. All things considered, for a complex existing building, it could be necessary to have multiple digital models, everyone for a given function but related one to each other.

The structural model (Tucci et al., 2018), which tends to simplify, will define the main elements without precise geometric accuracy but considering the future purpose of the model itself and the structural verifications it might will used for. Based on the accuracy decided a priori, the architectural model will have to describe specifically the elements and potentially also the historical phases, which allow understanding the actual building shape. Finally, the 
facility management model, which manages the building as a whole, deals with spaces, and the estimation of surfaces could be more streamlined.

Therefore, the BIM can hardly be a real and precise digital twin of the building. The model does not match perfectly with the survey point cloud despite the set tolerances (based on the chosen model type and its features) and the analysis of the available informative materials. The important thing is to define the adequate accuracy for the model, that is related to the construction on site and to the executive project. If, for a new construction, it is a consequence of project phase, for an existing building, it is essential to specify before starting the modelling phase. Furthermore, it is relevant for choosing the appropriate methodology for the survey phase in order to avoid unnecessary work. In this case, the laser scanner survey generated an extremely precise point cloud that allowed to analyze the building in its complexity and understand nodes that would not be caught by direct analysis and theodolite survey.

In order to better understand the modelling problem in Autodesk Revit, it is interesting to consider that in the facility management field often is not necessary to work with a precise model: software analyzes data and quantities and the actual shape is less significant for this kind of studies.

To summarize, it could be interesting to think about different models (with different simplification) and even manage the database related to the model as a precious item to further analyze in other software.

Talking about pre-existences and especially historical buildings, it is necessary to create elements with irregular geometries. This requirement is not always supported by Autodesk Revit, and it is indispensable to intervene with different software. This observation is supported by the constant current demand for a BIM model for any intervention on any type of building, new and existing. As described above, assuming to work with different models, BIM with simplified geometries is undoubtedly a useful and usable tool for various activities. Still, it is not adequate for detailed modelling of the built.

One thing is certain: if the world of construction and its standards are increasingly moving towards the BIM world, the evolution of the modelling of the preexistences is necessary. It is expected an update and a development of various BIM software in order to enhance the modelling of heritage buildings (irregulars and complexes). If that does not happen, it will be necessary to find a different method to intervene on this type of buildings because, especially in Italy, there is an elevated number of preexistence to valorize and to renovate. The effective solutions that involved different software and skills are adequate but the aim is to define a unique system that can be used by public administrations in order to respect the next deadline legislation.

\section{References}

Angelidou, M., Angelidou, T., Karachaliou, E., \& Stylianidis, E. (2017). Cultural heritage in smart city environments. Int. Arch. Photogramm, Remote Sens. Spatial Inf. Sci., XLII-2/W5, 27-32. https://doi.org/10.5194/isprs-archives-XLII-2W5-27-2017

Atta, N., \& Talamo, C. (2019). Digital transformation in facility management (FM). loT and big data for service innovation. In: Daniotti, B., Gianinetto, M., Della Torre, S. (ed) Digital Transformation of the Design, Construction and Management Processes of the Built Environment. Research for Development. Springer, Heidelberg, $267-278$. https://doi.org/10.1007/978-3-030-33570-0_24

Banfi, F. (2017). BIM orientation: grades of generation and information for different type of analysis and management process. Int. Arch. Photogramm, Remote Sens. Spatial Inf. Sci., XLII-2/W5, 57-64. https://doi.org/10.5194/isprsarchives-XLII-2-W5-57-2017

Banfi, F. (2020). HBIM, 3D drawing and virtual reality for archaeological sites and ancient ruins. Virtual Archaeology Review, 11(23), 16-33. https://doi.org/10.4995/var.2020.12416

Banfi, F., Stanga, C., \& Brumana, R. (2018). A Digital Workflow for Built Heritage: From SCAN-to-BIM process to the VRTour of the Basilica of Sant'Ambrogio in Milan. 7th International Conference, EuroMed 2018, Nicosia, Cyprus, October 29- November 3, 2018, Proceedings, Part I

Barazzetti, L., Banfi, F., Brumana, R., \& Previtali, M. (2015). Creation of Parametric BIM Objects from Point Cloud using NURBS. The Photogrammetric Record, 30(152), 339-362. https://doi.org/10.1111/phor.12122

Bie, R., Bocchi, Y., Genooud, D., Jara, A.J., Song, H., \& Sun, Y. (2015). Internet of things for cultural heritage of smart cities and smart regions. 29th International Conference on Advanced Information Networking and Applications Workshops, Gwangiu, South Korea, 2015, 668-675. https://doi.org/10.1109/WAINA.2015.169

BIMForum. (2018). Level of development specification.

Di Giuda, G. M., Paleari, F., Schievano, M., Seghezzi, E., Locatelli, M., Pattini, G., Pellegrini, L., Campi, S., \& Tucci, A. (2020). Linee guida Melzo BIM 1 - Modellazione informativa di interventi di nuova costruzione.

Di Giuda, G. M., Paleari, F., Schievano, M., Seghezzi, E., Locatelli, M., Pattini, G., Pellegrini, L., Campi, S., \& Tucci, A. (2020). Linee guida Melzo BIM 2 - Modellazione informativa di interventi su edifici esistenti.

Di Giuda, G. M., Paleari, F., Schievano, M., Seghezzi, E., Locatelli, M., Pattini, G., Pellegrini, L., Campi, S., \& Tucci, A. (2020). Linee guida Melzo BIM 3 - Modellazione informativa di interventi di manutenzione ordinaria e straordinaria.

Guzzetti, F., Anyabolu, K. L. N., D’Ambrosio, L., Marchetti, G., \& Sarrecchia, S. (2018). Dal rilievo al modello BIM di una 
piazza. XXII Conferenza Nazionale ASITA, 27-29 novembre 2018, Bolzano, 577-584

Guzzetti, F., Anyabolu, K. L. N., D’Ambrosio, L., \& Marchetti Guerrini, G. (2019). Built environment: modelling the Urban Space. Int. Arch. Photogramm. Remote Sens. Spatial Inf. Sci., XLII-2/W11, 595-600. https://doi.org/10.5194/isprsarchives-XLII-2-W11-595-2019

Lerario, A., \& Varesano, A. (2020). An loT smart infrastructure for S. Domenico church in Matera's "Sassi": a multiscale perspective to built heritage conservation. Sustainability, 12(16). https://doi.org/10.3390/su12166553

Lopez, F. J., Lerones, P. M., Llamas, J., Gomez-Garcia-Bermejo, J., \& Zalama, E. (2018). A review of Heritage Building Information Modeling (H-BIM). Multimedial Technologes and Interact, 2(21). https://doi.org/10.3390/mti2020021

Ministerial Decree, (2017). Ministerial Decree, 1-12-2017, n. 560, Ministry of Infrastructure and Transport, Italy

Mirarchi, C., Lupica Spagnolo, S., Daniotti, B., \& Pavan, A. (2020). Structuring General Information Specifications for Contracts in Accordance with the UNI 11337:2017 Standard. In: Daniotti B, Gianinetto M, Della Torre (Eds.) Digital Transformation of the Design, Construction and Management Process of the Built environmrnt. Research for Development. Springer, Cham. https://doi.org/10.1007/978-3-030-33570-0_10

Osello, A., Lucibello, G., \& Morgagni, F. (2018). HBIM and virtual tools: a new chance to preserve architectural heritage. Techne, 13, 21-26. https://doi.org/10.3390/buildings8010012

Qiuchen, L., \& Sanghoon, L. (2017). Image-based technologies for constructing as-is building information models for existing buildings. Journal of Computing in Civil Engineering, 31(4). https://doi.org/10.1061/(ASCE)CP.19435487.0000652

Stanga, C., Spinelli, C., Brumana, R., Oreni, D., Valente, R., \& Banfi, F. (2017). A N-D virtual notebook about the Basilica of S. Ambrogio in Milan: information modeling for the communication of historical phases subtraction process. Int. Arch. Photogramm, Remote Sens. Spatial Inf. Sci., XLII/W5, 653-660. https://doi.org/10.5194/isprs-archives-XLII-2W5-653-2017

Tommasi, C., Fiorillo, F., Jiménez Fernàndez-Palacios, B., \& Achille, C. (2019). Access and web-sharing of 3D digital documentation of environmental and architectural heritage. Int. Arch. Photogramm, Remote Sens. Spatial Inf. Sci., XLII-2/W9, 707-714. https://doi.org/10.5194/isprs-archives-XLII-2-W9-707-2019

Tucci, G., Bartoli, G., Betti, M., Bonora, V., Korumaz, M., \& Korumaz, A. G. (2018). Advanced procedure for documenting and assessment of Cultural Heritage: from Laser Scanning to Finite Element. IOP Conf. Series: Materials Science and Engineering, 364. https://doi.org/10.1088/1757-899X/364/1/012085

UNI (2017). UNI 11337:2017 - Building and civil engineering works - Digital management of the informative processes 